\title{
Efeito de extratos vegetais aquosos sobre a mosca-das-frutas Ceratitis capitata (Wiedemann) (Diptera: Tephritidae)
}

\author{
Effect of aqueous plant extracts on the fruit fly Ceratitis capitata \\ (Wiedemann) (Diptera: Tephritidae)
}

\author{
Cristhiane Rohde ${ }^{*}$, Alcides Moino Júnior², Patrícia Krupa Silva ${ }^{3}$, Kaio Roger de Oliveira Ramalho ${ }^{3}$
}

RESUMO: O objetivo deste trabalho foi avaliar o efeito de extratos vegetais para o controle de Ceratitis capitata. Os tratamentos foram extratos aquosos preparados com vegetais frescos e secos na proporçáo de $20 \% \mathrm{p} / \mathrm{v}$ (peso do vegetal/volume de água) da folha, do ramo e do fruto de cinamomo, da folha de arruda, do alho e do gengibre. Para a avaliação sobre a fase imatura, cada repetição foi constituída de uma placa com 20 larvas ou 20 pupas, as quais foram imersas em $1 \mathrm{~mL}$ de extrato durante 30 segundos. Para o extrato preparado com os frutos secos de cinamomo, foram avaliadas as concentraçóes de 0,5 , $10,15,10$ e $25 \%$ p/v. As avaliações foram realizadas após cinco dias, contando-se o número de larvas mortas, de pupas inviáveis e de adultos deformados. Para a fase adulta, foram avaliados apenas os extratos preparados com vegetais secos. Cada repetição foi constituída de um pote plástico contendo um fruto de ameixa vermelha e um rolete de algodão embebido com $5 \mathrm{~mL}$ de extrato. Foram transferidas três fêmeas e dois machos de C. capitata para cada pote plástico. Após dois dias, realizou-se a avaliaçáo da mortalidade de adultos e a retirada dos frutos, os quais foram individualizados, e após sete dias contou-se o número de larvas desenvolvidas. Verificou-se que todos os extratos reduziram o número de insetos viáveis, com destaque para o de cinamomo, o qual teve efeito também sobre a fase adulta. Nas condiçôes estudadas, nenhum extrato teve resultado sobre a fecundidade das fêmeas de C. capitata.

PALAVRAS-CHAVE: mosca-do-mediterrâneo; Melia azedarach; Ruta graveolens; Allium sativum; Zingiber officinale.

\begin{abstract}
The aim of this study was to evaluate the effect of vegetable extracts to control Ceratitis capitata. The treatments were aqueous extracts prepared with fresh and dry vegetables at a $20 \% \mathrm{w} / \mathrm{v}$ (weight plant/water volume) rate of chinaberry leaf, twig and fruit, rue leaf, garlic, and ginger. For the immature phase evaluation, each repetition consisted of a plaque with 20 larvae or 20 pupae, which were dipped in $1 \mathrm{~mL}$ of extract for 30 seconds. For the extract prepared with chinaberry dry fruits, concentrations of $0,5,10,15,10$, and $25 \% \mathrm{w} / \mathrm{v}$ were evaluated. Analyses were made after five days by counting the number of dead larvae or pupae and the number of deformed adults. For the adult phase, only the extracts prepared with dried vegetables were assessed. Each repetition included a plastic jar containing a red plum fruit and a cotton roller soaked with $5 \mathrm{~mL}$ of extract. For each plastic container, three females and two males of C. capitata were transferred. After two days, the assessment of adult mortality and fruit withdrawal, which were individualized, were carried out. After seven days, the amount of larvae developed in each fruit was counted. It was found that all extracts reduced the number of viable insects, especially the chinaberry one, which also had an effect on the adult phase. In the studied conditions, no extract had effects on the fertility of $C$. capitata females.
\end{abstract}

KEYWORDS: Mediterranean fruit fly; Melia azedarach; Ruta graveolens; Allium sativum; Zingiber officinale.

\footnotetext{
'Colegiado de Agronomia, Universidade Federal da Fronteira Sul (UFFS) - Laranjeiras do Sul (PR), Brasil.

${ }^{2}$ Departamento de Agronomia, Universidade Federal de Lavras (UFLA) - Lavras (MG), Brasil.

${ }^{3}$ Universidade Estadual do Centro-Oeste (Unicentro) - Guarapuava (PR), Brasil.

*Autor correspondente: cristhiane.rohde@uffs.edu.br

Recebido em: 18/04/2012. Aceito em: 16/08/2013
} 


\section{INTRODUÇÃO}

As moscas-das-frutas (Diptera: Tephritidae) causam perdas significativas à fruticultura mundial devido a seus danos diretos, os quais ocorrem em consequência da oviposição realizada pelas fêmeas nos frutos e pelo consumo dos frutos pelas larvas, e indiretos, pois facilitam a entrada de micro-organismos no fruto. Além disso, são consideradas pragas quarentenárias, o que acarreta limitaçâo do livre trânsito de frutas frescas, pelas restriçóes impostas por este tipo de medida dos países importadores (White; ÉLSON-Harris, 1992).

No Brasil, apresentam importância econômica as moscas-das-frutas pertencentes aos gêneros Anastrepha Schiner e Ceratitis MacLeay. Dentro do gênero Ceratitis, destaca-se a espécie C. capitata (Wiedemann) (mosca-do-mediterrâneo), a qual é reconhecida como uma das mais sérias pragas da fruticultura em escala mundial, devido ao fato de estar distribuída em todas as regiôes biogeográficas do mundo, além da sua diversidade de hospedeiros, da natureza do dano causado e da sua grande adaptabilidade ao meio (ZuCCHI, 2001).

Atualmente, o controle da mosca-das-frutas pode ser realizado por meio dos métodos culturais, da técnica do inseto estéril, dos controles legislativo, biológico e químico, sendo o último o mais utilizado (Nascimento; Carvalho, 2000). No entanto, esta forma de controle, tanto em pulverização em cobertura, quanto em isca tóxica, contribui de forma acentuada para o desequilíbrio do agroecossistema, atingindo os inimigos naturais e outros organismos náo alvos, além de deixar resíduos tóxicos nos frutos, prejudicando a comercialização e o consumo do fruto in natura.

Dessa forma, têm sido desenvolvidas pesquisas voltadas à utilização de medidas de controle, as quais proporcionem menor impacto ambiental e que sejam compatíveis com os programas de manejo integrado das pragas. Nesse sentido, as plantas inseticidas e seus extratos aparecem como importantes ferramentas, pois apresentam favoráveis propriedades toxicológicas, rápida degradação, menor efeito sobre organismos não alvos e sobre o meio ambiente, além de maior segurança para o consumidor (VASCONCELOS et al., 2006).

Os efeitos inseticidas de determinadas plantas e seus extratos ocorrem principalmente devido à presença de substâncias produzidas pelo metabolismo secundário do vegetal em resposta ao ataque de insetos. Essas substâncias bioativas podem ser encontradas em raízes, caules, folhas, sementes e frutos, dentre as quais destacam-se: limonoides, rotenoides, piretroides, alcaloides e terpenoides, que podem interferir severamente no metabolismo dos insetos, causando impactos variáveis, tais como repelência, deterrência alimentar e de oviposição, esterilização, bloqueio no metabolismo e interferência no desenvolvimento, podendo ou náo causar a morte (Medeiros, 1990). No último caso, pode haver apenas retardamento no desenvolvimento do inseto, causando efeito insetistático (Hernandez; Vendramim, 1998). Extratos de diferentes plantas têm sido estudados para o controle de diversos insetos-praga, tendo sido obtidos resultados promissores (CARpinella et al., 2003; SANTiago et al., 2008; SANTOS et al., 2012). Para a mosca-das-frutas C. capitata, verificou-se a ação inseticida do extrato da casca de limão Citrus limonia (Rutaceae) e de Cestrum parqui (Solanaceae), quando incorporado na dieta de larvas e adultos (SAlvatore et al., 2004; ZaPpata et al., 2006).

Desse modo, são necessários novos estudos a fim de determinar a descoberta de novas espécies com potencial para serem utilizadas na forma de extratos vegetais ao controle de insetos-praga. Assim, o objetivo deste trabalho foi avaliar o efeito de extratos preparados com diferentes vegetais frescos e secos sobre larvas, pupas e adultos de C. capitata.

\section{MATERIAL E MÉTODOS}

\section{Criação de Ceratitis capitata}

Para o início da criação, foram utilizadas pupas provenientes do Centro de Energia Nuclear na Agricultura - CENA (Piracicaba, São Paulo). A criação foi mantida em condiçôes controladas de temperatura de $25 \pm 2^{\circ} \mathrm{C}$, umidade relativa de $70 \pm 10 \%$ e fotofase de 12 horas, segundo metodologia proposta por SiLVA (1990).

\section{Obtenção dos extratos vegetais}

Foram utilizados extratos aquosos preparados com vegetais frescos e secos de folha, ramo e fruto de cinamomo (Melia azedarach) (Meliaceae), folha de arruda (Ruta graveolens) (Rutaceae), gengibre (Zingiber officinalis) (Zingiberaceae) e alho (Allium sativum) (Lililaceae), coletados no município de Guarapuava, no Estado do Paraná.

Para obtenção dos extratos preparados com vegetais frescos, eles foram colhidos e triturados em processador elétrico com água destilada na proporção de $20 \% \mathrm{p} / \mathrm{v}$ (peso do vegetal fresco antes da trituração/volume de água) e deixados em repouso durante 24 horas, em uma sala climatizada $\left(25 \pm 2^{\circ} \mathrm{C}\right.$, sem fotofase). Para obtenção dos extratos preparados com vegetais secos, esses foram mantidos em uma estufa a $90 \pm 2^{\circ} \mathrm{C}$ durante cinco dias, moídos e diluídos em água destilada na proporção de $20 \% \mathrm{p} / \mathrm{v}$ (peso do vegetal seco em pó/volume de água) e deixados em repouso durante 24 horas, nas mesmas condiçôes descritas anteriormente. Após tal período, as suspensóes foram filtradas para posterior aplicação sobre os insetos. 


\section{Avaliação de extratos preparados com vegetais frescos e secos sobre larvas e pupas de $C$. capitata}

Foram realizados dois experimentos: um para avaliar o efeito dos extratos preparados com vegetais frescos e secos sobre a fase larval e o outro sobre as pupas de C. capitata, os quais foram conduzidos em delineamento inteiramente casualizado, com sete repetiçóes por tratamento. Cada unidade amostral foi constituída de uma placa de Petri com papel filtro, incluindo 20 larvas no final do terceiro instar ou 20 pupas com idades entre cinco e oito dias. Os indivíduos foram transferidos para um copo plástico, aplicando-se $1 \mathrm{~mL}$ de cada extrato vegetal a $20 \% \mathrm{p} / \mathrm{v}$. Após 30 segundos de contato, eles foram acondicionados em placas de Petri. No tratamento testemunha foi aplicado $1 \mathrm{~mL}$ de água destilada. Os experimentos foram mantidos em câmara climatizada $\left(25 \pm 2^{\circ} \mathrm{C}, 70 \pm 10 \%\right.$ de umidade, fotofase de 12 horas). A avaliação foi realizada após dez dias, contando-se o número de larvas mortas, pupas inviáveis e adultos com deformação. Os dados foram submetidos à análise de variância (teste $\mathrm{F}$ ), e as médias foram comparadas entre si pelo teste de Scott-Knott ( $\mathrm{p} \leq 0,05)$, com auxílio do programa Sisvar (FerReira, 2000).

\section{Avaliação de diferentes concentrações do extrato de fruto de cinamomo (Melia azedarach) preparado a seco sobre larvas e pupas de $C$. capitata}

Para tais experimentos foi utilizado apenas o extrato obtido a seco do fruto de cinamomo, pois foi o que apresentou o melhor resultado anteriormente. Avaliou-se o efeito de diferentes concentraçôes do extrato de cinamomo sobre larvas e pupas de C. capitata. Adotou-se o delineamento inteiramente casualizado, com sete repetiçôes por tratamento. Cada unidade amostral foi constituída por uma placa de Petri com papel filtro incluindo 20 larvas no final do terceiro instar ou 20 pupas com idades entre cinco e oito dias. Larvas e pupas foram imersas em copos plásticos contendo $1 \mathrm{~mL}$ do extrato de fruto de cinamomo a $0,5,10,15,20 \mathrm{e}$ $25 \%$ p/v e, após 30 segundos de contato, foram acondicionados em placas de Petri. Os experimentos foram mantidos em câmara climatizada $\left(25 \pm 2^{\circ} \mathrm{C}, 70 \pm 10 \%\right.$ de umidade, fotofase de 12 horas). A avaliação foi realizada após dez dias, contando-se o número de larvas mortas, pupas inviáveis e adultos com deformação. As informaçôes foram submetidas à análise de variância (teste $\mathrm{F}$ ) e as médias foram estudadas por meio de regressáo $(\mathrm{p} \leq 0,05)$, com auxílio do programa Sisvar (FERREIRA, 2000).

\section{Avaliação de extratos preparados com vegetais secos sobre adultos de $C$. capitata}

O experimento foi conduzido em delineamento inteiramente casualizado, com sete repetiçóes por tratamento. Cada unidade amostral foi constituída de um pote plástico (capacidade para $2 \mathrm{~L}$ ) com tampa plástica, incluindo um fruto de ameixa-vermelha (Prunus sp.) (Rosaceae), preso no fundo do pote e um rolete de algodáo $(2 \times 1 \mathrm{~cm})$ embebido com $5 \mathrm{~mL}$ de cada extrato preparado com vegetais secos. Os frutos foram imersos na solução do extrato vegetal e, após estarem secos, foram acondicionados nos potes plásticos. No tratamento testemunha foi utilizada água destilada. Em cada unidade amostral foram transferidas três fêmeas e dois machos de C. capitata, com idades entre cinco e sete dias, que haviam permanecido 24 horas sem acesso a um alimento. O experimento foi mantido em sala climatizada $\left(25 \pm 2^{\circ} \mathrm{C}\right.$, $70 \pm 10 \%$ de umidade, fotofase de 12 horas).

Após dois dias, realizou-se a avaliação da mortalidade de adultos de C. capitata e a retirada dos frutos, os quais foram individualizados em potes plásticos (capacidade de $200 \mathrm{~mL})$ e mantidos em sala climatizada $\left(15 \pm 2^{\circ} \mathrm{C}, 70 \pm\right.$ $10 \%$ de umidade, fotofase de 12 horas) durante sete dias para contagem do número de larvas desenvolvidas em cada fruto. Os dados foram submetidos à análise de variância (teste $\mathrm{F}$ ), e as médias foram comparadas entre si pelo teste de Scott-Knott ( $\mathrm{p}$ 0,05), com auxílio do programa Sisvar (FerReira, 2000).

\section{RESULTADOS E DISCUSSÃO}

\section{Avaliação de extratos preparados com vegetais frescos e secos sobre larvas e pupas de $C$. capitata}

Os extratos vegetais preparados a fresco, com exceção do de arruda, tiveram efeito inseticida sobre as larvas de C. capitata, diferindo-se do tratamento testemunha. No entanto, somente os extratos de folha e o ramo de cinamomo afetaram o número de adultos normais emergidos (Tabela 1). Para a fase de pupa deste inseto, todos os extratos tiveram resultado, aumentando a porcentagem de pupas inviáveis. Porém, somente aqueles obtidos da planta de cinamomo (fruto, folha e ramo) reduziram o número de adultos normais emergidos (Tabela 2).

Ao analisar a porcentagem total de insetos inviáveis (larvas mortas e adultos deformados), verificou-se que o extrato de alho teve a melhor açáo sobre a fase larval, seguido dos 
extratos obtidos de diferentes estruturas da planta de cinamomo. Para a fase de pupa, notou-se que todos os extratos causaram redução no número de insetos viáveis (pupas inviáveis mais adultos mortos).

Em relação aos extratos preparados a seco, todos tiveram efeito sobre larvas e pupas de C. capitata e, assim como observado para os extratos preparados a fresco, aqueles obtidos a partir das plantas de cinamomo (fruto, folha ou ramo) causaram maior redução no número de adultos normais emergidos (Tabelas 3 e 4).

Observando a porcentagem total de insetos inviáveis, os extratos obtidos da planta de cinamomo foram os mais eficientes contra larvas e pupas de C. capitata, com destaque para aquele derivado dos frutos de cinamomo.

O principal efeito de extratos obtidos a partir das plantas de cinamomo sobre os insetos é a fagoinibição ou deterrência, causada por substâncias como limonoides e triterpenoides (CArpinella et al., 2003). Outro efeito que os limonoides e os pinoresinois, encontrados em plantas de cinamomo, podem causar sobre os insetos é a interferência no processo de ecdise e metamorfose, aumentando a mortalidade e o número de insetos deformados (CABral et al., 1999; Dequech et al., 2008; ANDrade-Coelho et al., 2009).

Tabela 1. Porcentagem de mortalidade média ( \pm EP) de larvas mortas e adultos deformados após dez dias da aplicação de diferentes extratos preparados com vegetais frescos sobre a fase larval de Ceratitis capitata $\left(25 \pm 2^{\circ} \mathrm{C}, 70 \pm 10 \%\right.$ de umidade, fotofase de 12 horas).

\begin{tabular}{lccc} 
Tratamentos & \% de mortalidade de larvas & \% de adultos deformados & \% total de insetos inviáveis $^{1,2}$ \\
\hline Testemunha & $0,71 \pm 0,71 \mathrm{~d}$ & $0,71 \pm 1,01 \mathrm{~b}$ & $1,42 \pm 1,42 \mathrm{c}$ \\
\hline Folha de cinamomo & $0,00 \pm 0,00 \mathrm{~d}$ & $11,43 \pm 2,10 \mathrm{a}$ & $11,43 \pm 2,10 \mathrm{~b}$ \\
\hline Ramo de cinamomo & $2,86 \pm 1,01 \mathrm{c}$ & $10,71 \pm 1,70 \mathrm{a}$ & $13,57 \pm 1,89 \mathrm{~b}$ \\
\hline Gengibre & $10,71 \pm 0,71 \mathrm{~b}$ & $0,00 \pm 0,00 \mathrm{~b}$ & $10,71 \pm 0,71 \mathrm{~b}$ \\
\hline Alho & $20,71 \pm 1,30 \mathrm{a}$ & $0,00 \pm 0,00 \mathrm{~b}$ & $20,71 \pm 1,30 \mathrm{a}$ \\
\hline Arruda & $2,14 \pm 1,01 \mathrm{c}$ & $0,00 \pm 0,00 \mathrm{~b}$ & $2,14 \pm 1,01 \mathrm{c}$ \\
\hline CV (\%) & 46,05 & 50,53 & 31,08 \\
\hline
\end{tabular}

'médias seguidas da mesma letra na mesma coluna não diferem entre si pelo teste Scott-Knott ( $\leq \leq 0,05 \%)$;

${ }^{2}$ dados originais em porcentagem apresentados e transformados em $\operatorname{arcsen} \sqrt{\mathrm{x} / 100}$ para análise.

Tabela 2. Porcentagem média ( \pm EP) de pupas inviáveis e adultos deformados após dez dias da aplicação de diferentes extratos preparados com vegetais frescos sobre a fase de pupa de Ceratitis capitata $\left(25 \pm 2^{\circ} \mathrm{C}, 70 \pm 10 \%\right.$ de umidade, fotofase de 12 horas).

\begin{tabular}{lccc} 
Tratamentos & \% pupas inviáveis & & \% de adultos deformados \\
Testemunha & $2,14 \pm 1,01 \mathrm{c}$ & \% total de insetos inviáveis $^{1,2}$ \\
\hline Fruto de cinamomo & $18,57 \pm 1,80 \mathrm{~b}$ & $1,43 \pm 0,92 \mathrm{~b}$ & $3,57 \pm 1,43 \mathrm{c}$ \\
\hline Folha de cinamomo & $26,43 \pm 0,92 \mathrm{a}$ & $13,71 \pm 1,30 \mathrm{a}$ & $34,28 \pm 2,30 \mathrm{a}$ \\
\hline Ramo de cinamomo & $17,14 \pm 1,01 \mathrm{~b}$ & $16,43 \pm 1,43 \mathrm{a}$ & $40,00 \pm 1,89 \mathrm{a}$ \\
\hline Gengibre & $17,86 \pm 1,01 \mathrm{~b}$ & $0,71 \pm 0,71 \mathrm{~b}$ & $33,57 \pm 1,80 \mathrm{a}$ \\
\hline Alho & $27,86 \pm 1,49 \mathrm{a}$ & $0,71 \pm 0,71 \mathrm{~b}$ & $18,57 \pm 1,43 \mathrm{~b}$ \\
\hline Arruda & $30,71 \pm 1,30 \mathrm{a}$ & $0,00 \pm 0,00 \mathrm{~b}$ & $28,57 \pm 1,43 \mathrm{a}$ \\
\hline CV (\%) & 13,32 & 37,30 & $30,71 \pm 1,30 \mathrm{a}$ \\
\hline
\end{tabular}

'médias seguidas da mesma letra na mesma coluna não se diferem entre si pelo teste Scott-Knott $(p \leq 0,05 \%)$;

${ }^{2}$ dados originais em porcentagem apresentados e transformados em arcsen $\sqrt{\mathrm{x} / 100}$ para análise.

Tabela 3. Porcentagem de mortalidade média ( \pm EP) de larvas mortas e adultos deformados após dez dias da aplicação de diferentes extratos preparados com vegetais secos sobre a fase larval de Ceratitis capitata ( $25 \pm 2^{\circ} \mathrm{C}, 70 \pm 10 \%$ de umidade, fotofase de 12 horas).

\begin{tabular}{lccc} 
Tratamentos & \% mortalidade de larvas & \% de adultos deformados & \% total de insetos inviáveis \\
Testemunha & $1,43 \pm 0,92 \mathrm{c}$ & $0,00 \pm 0,00 \mathrm{c}$ & $1,43 \pm 0,92 \mathrm{~d}$ \\
\hline Fruto de cinamomo & $31,43 \pm 1,09 \mathrm{a}$ & $25,00 \pm 2,67 \mathrm{a}$ & $56,43 \pm 2,83 \mathrm{a}$ \\
\hline Folha de cinamomo & $8,57 \pm 2,03 \mathrm{~b}$ & $12,14 \pm 2,40 \mathrm{~b}$ & $20,71 \pm 2,30 \mathrm{~b}$ \\
\hline Ramo de cinamomo & $7,86 \pm 1,01 \mathrm{~b}$ & $11,43 \pm 2,10 \mathrm{~b}$ & $19,29 \pm 2,54 \mathrm{~b}$ \\
\hline Gengibre & $6,43 \pm 0,92 \mathrm{~b}$ & $0,00 \pm 0,00 \mathrm{c}$ & $6,43 \pm 0,92 \mathrm{c}$ \\
\hline Alho & $6,43 \pm 0,92 \mathrm{~b}$ & $0,71 \pm 0,71 \mathrm{c}$ & $7,14 \pm 1,01 \mathrm{c}$ \\
\hline Arruda & $8,57 \pm 1,37 \mathrm{~b}$ & $0,00 \pm 0,00 \mathrm{c}$ & $8,57 \pm 1,37 \mathrm{c}$ \\
\hline CV (\%) & 20,25 & 36,25 & 18,87 \\
\hline
\end{tabular}

'médias seguidas da mesma letra na mesma coluna não se diferem entre si pelo teste Scott-Knott $(p \leq 0,05 \%)$;

${ }^{2}$ dados originais em porcentagem apresentados e transformados em $\operatorname{arcsen} \sqrt{\mathrm{x} / 100}$ para análise. 
No presente trabalho, a elevada eficiência do extrato de cinamomo se deveu à interferência no processo de ecdise e metamorfose de C. capitata e náo à deterrência, já que foram utilizadas larvas no final do terceiro instar e pupas nos bioensaios, as quais não se alimentam. Este resultado sobre a ecdise e a metamorfose também explica o grande número de adultos deformados emergidos a partir dos imaturos tratados principalmente com os extratos de cinamomo.

SAlLEs; Rech (1999) observaram que o extrato de cinamomo causou um acréscimo no número de pupas e adultos deformados de Anastrepha fraterculus (Diptera: Tephritidae). Também houve aumento na quantia de adultos deformados e elevada mortalidade de larvas de Drosophila melanogaster (Diptera: Drosophilidae) e prolongaçáo no período de desenvolvimento de larvas e reduçáo no peso de pupas da mosca-doméstica Musca domestica (Diptera: Muscidae), quando expostas aos extratos de folhas e frutos de cinamomo (Chiffelle et al., 2009; Cabral et al., 2008). AndradeCoelho et al. (2009) também observaram elevada mortalidade e insetos deformados, devido à inibição na ecdise de larvas de Lutzomyia longipalpis (Diptera: Psychodidae) quando expostas aos extratos de folhas e frutos de cinamomo.

A maior eficiência do extrato do fruto de cinamomo em relação àqueles obtidos da folhas e dos ramos está relacionada às variaçóes na composição e concentraçáo de metabólitos secundários que ocorrem nas diferentes partes vegetais da planta (Costa et al., 2004).

Brunherotto e Vendramim (2000) também observaram variaçốes na eficiência dos extratos de folhas, ramos e frutos de cinamomo sobre Tuta absoluta (Lepidoptera: Gelechiidae). Igualmente ao observado no presente trabalho, esses autores verificaram que todos os extratos obtidos das diferentes partes da planta de cinamomo afetaram negativamente o desenvolvimento do inseto, sugerindo que os ingredientes ativos estão presentes nas diversas estruturas da planta, embora em concentraçóes variáveis.

Variaçôes também são notadas nos diferentes estágios fenológicos da planta. Nesse sentido, Chiffelle et al. (2009) verificaram que extratos preparados com folhas novas e frutos verdes foram mais eficazes em relação àqueles com folhas velhas e frutos maduros. Diante destas variações, são necessários novos estudos para determinar a composiçáo química de cada parte vegetal e os diferentes estágios fenológicos da planta, possibilitando, assim, a produção de extratos vegetais mais eficientes.

O extrato de arruda também teve efeito sobre a fase de pupa de C. capitata, quando preparado a fresco e a seco, causando mortalidade superior a $30 \%$, porém aquele sobre a fase de larva foi pequeno, com mortalidade inferior a $10 \%$.

O efeito inseticida do extrato de arruda também já foi observado para outros insetos (Almeida et al., 1999; Santiago et al., 2008; Barbosa et al., 2009; 2011). Assim como para os extratos de cinamomo, a ação inseticida da arruda também está relacionada com a presença dos limonoides. Além disso, possuem outros compostos tais como glicosídeos, lactonas aromáticas, alcaloides, flavonoides e terpenos, os quais podem ter açâo inseticida (MarTins et al., 2005).

Já o extrato de alho teve ação inseticida sobre a fase larval e de pupa de $C$. capitata. No entanto, não foram encontrados trabalhos explicando o mecanismo de ação do extrato ou avaliando o seu potencial contra os insetos. Menezes (2005) observou que o extrato de alho apresenta açáo sistêmica sobre a planta, causando repelência sobre os insetos. Mas de acordo com os resultados aqui obtidos, há indícios que este extrato vegetal também apresente efeito inseticida.

$\mathrm{O}$ extrato de gengibre apresentou a menor eficiência sobre C. capitata, quando comparado aos demais estudados. Também não foram encontrados trabalhos explicando o mecanismo de açấo do mesmo. Mas o efeito inseticida desse extrato também já foi observado para outros insetos, como o pulgão Toxoptera citricida (Hemiptera: Aphididae) (SiLva et al., 2009).

Os extratos vegetais preparados a seco foram mais eficientes contra C. capitata, causando redução máxima de 56,4 e $62,9 \%$ no número de insetos viáveis, quando aplicados

Tabela 4. Porcentagem média ( \pm EP) de pupas inviáveis e adultos deformados após dez dias da aplicação de diferentes extratos preparados com vegetais secos sobre a fase de pupa de Ceratitis capitata ( $25 \pm 2^{\circ} \mathrm{C}, 70 \pm 10 \%$ de umidade, fotofase de 12 horas).

\begin{tabular}{lccc} 
Tratamentos & \% pupas inviáveis ${ }^{1,2}$ & \% de adultos deformados ${ }^{1,2}$ & \% total de insetos inviáveis $^{1,2}$ \\
\hline Testemunha & $2,86 \pm 1,01 \mathrm{~b}$ & $0,00 \pm 0,00 \mathrm{~d}$ & $2,86 \pm 1,01 \mathrm{c}$ \\
\hline Fruto de cinamomo & $32,86 \pm 2,86 \mathrm{a}$ & $30,00 \pm 2,67 \mathrm{a}$ & $62,86 \pm 4,61 \mathrm{a}$ \\
\hline Folha de cinamomo & $31,43 \pm 4,19 \mathrm{a}$ & $19,29 \pm 1,70 \mathrm{~b}$ & $50,71 \pm 4,93 \mathrm{a}$ \\
\hline Ramo de cinamomo & $38,57 \pm 2,10 \mathrm{a}$ & $21,43 \pm 1,80 \mathrm{~b}$ & $60,00 \pm 1,89 \mathrm{a}$ \\
\hline Gengibre & $30,71 \pm 4,00 \mathrm{a}$ & $3,57 \pm 2,10 \mathrm{c}$ & $34,29 \pm 5,05 \mathrm{~b}$ \\
\hline Alho & $37,14 \pm 3,76 \mathrm{a}$ & $0,00 \pm 0,00 \mathrm{~d}$ & $37,14 \pm 3,76 \mathrm{~b}$ \\
\hline Arruda & $34,29 \pm 5,17 \mathrm{a}$ & $0,71 \pm 0,71 \mathrm{~d}$ & $35,00 \pm 4,88 \mathrm{~b}$ \\
\hline CV (\%) & 18,16 & 34,03 & 15,70 \\
\hline
\end{tabular}

'médias seguidas da mesma letra na mesma coluna não se diferem entre si pelo teste Scott-Knott $(p \leq 0,05 \%)$;

${ }^{2}$ dados originais em porcentagem apresentados e transformados em $\operatorname{arcsen} \sqrt{\mathrm{x} / 100}$ para análise. 
sobre larvas e pupas, respectivamente, sendo que eles causaram redução máxima de 20,7 (larvas) e 40,0\% (pupas) no número de insetos viáveis.

Apesar da utilização dos extratos preparados com vegetais frescos e secos ter sido na mesma proporção de $20 \% \mathrm{p} / \mathrm{v}$ (peso do vegetal/volume de água), a concentração dos componentes no último foi superior. Isso occorreu devido ao fato de ter sido utilizado o peso do vegetal desidratado, enquanto que, no primeiro, o fresco, sendo essa a provável causa da maior eficiência dos extratos preparados com vegetais secos. Além disso, o processo de obtenção do extrato a seco pode ser mais eficiente para extrair as substâncias bioativas presentes na planta.

Além dos extratos preparados com vegetais secos terem apresentado maior eficiência para o controle de $C$. capitata, estes têm a vantagem de poderem ser estocados pelo produtor, possibilitando a utilização de plantas ou de partes das plantas sazonais durante o ano todo para o controle de pragas.

\section{Avaliação das diferentes concentrações do extrato de fruto de cinamomo (Melia azedarach) preparado a seco sobre larvas e pupas de $C$. capitata}

As fases de larva e de pupa de C. capitata foram suscetíveis a todas as concentraçóes estudadas do extrato de fruto de cinamomo, sendo que a mortalidade e o número de adultos

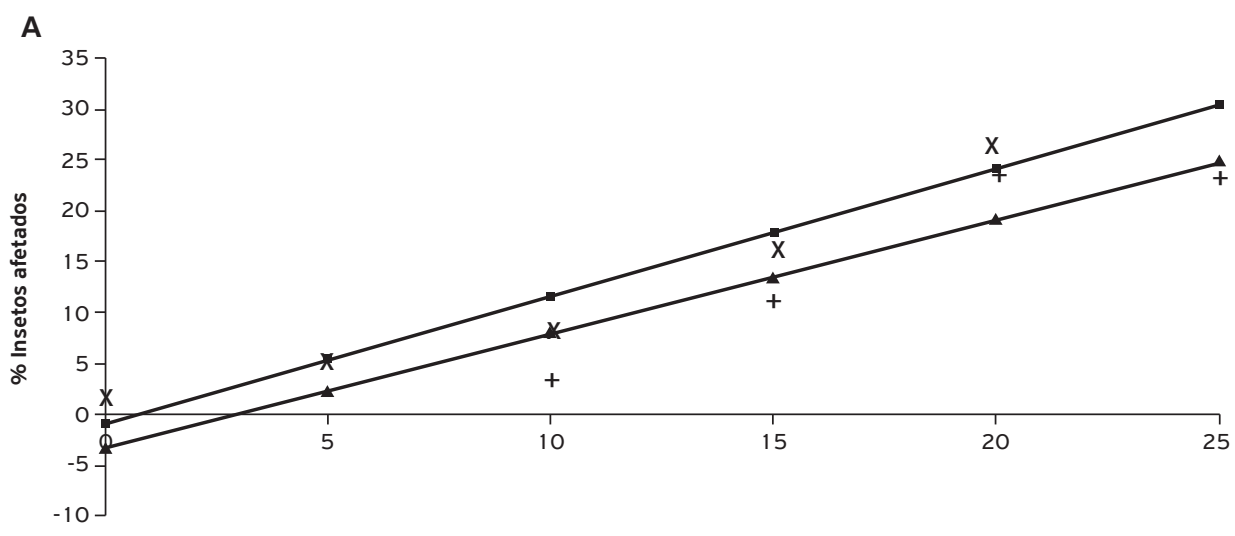

Concentração extrato cinamomo $(p / v)$

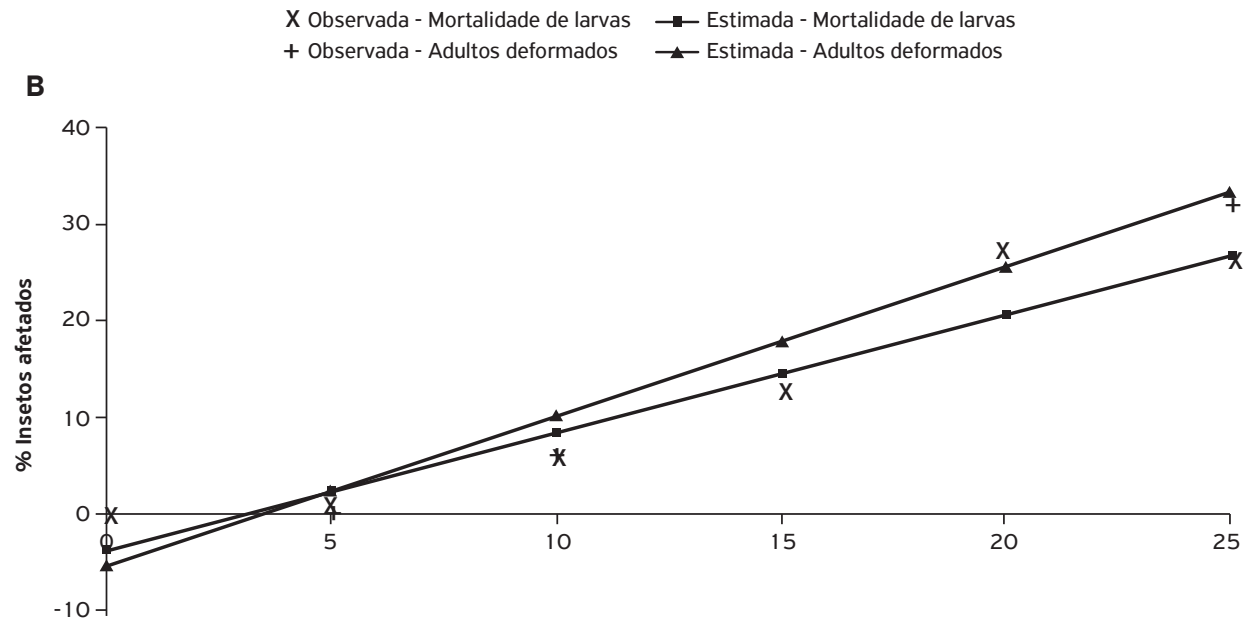

Concentração extrato cinamomo $(p / v)$

X Observada - Pupas inviáveis $\rightarrow$ Estimada - Pupas inviáveis

+ Observada - Adultos deformados $\rightarrow$ Estimada - Adultos deformados

Figura 1. (A) Porcentagem de mortalidade de larvas $\left(Y=-0,952381+1,257143 x, R^{2}=93,38\right)$ e adultos deformados $\left(Y=-3,367347+1,126531 x, R^{2}=90,38\right)$; e pupas inviáveis $\left(Y=-3,707483+1,220408 x, R^{2}=86,01\right) e$ (B) adultos deformados $\left(Y=-5,238095+1,542857 x, R^{2}=89,95\right)$, após cinco dias da aplicação de diferentes concentrações do extrato de cinamomo preparado a seco sobre Ceratitis capitata $\left(25 \pm 2^{\circ} \mathrm{C}, 70 \pm 10 \%\right.$ de umidade, fotofase de 12 horas). 
deformados foram diretamente proporcionais ao aumento da concentração do extrato vegetal (Fig. 1).

As duas concentraçóes mais elevadas do extrato vegetal causaram um efeito semelhante sobre larvas e pupas de C. capitata. Analisando as médias observadas, houve um aumento inferior a 5 e $1 \%$ na mortalidade de larvas e no número de pupas inviáveis, respectivamente, quando a concentração variou de 20 para $25 \% \mathrm{p} / \mathrm{v}$ do extrato vegetal.

As mortalidades mínima e máxima das larvas de C. capitata foram de 4 e $30 \%$, quando expostas à menor e maior concentração do extrato de cinamomo, respectivamente. Já o número de pupas inviáveis variou entre 1 e $26 \%$ quando expostas às diferentes concentraçôes do extrato de cinamomo.

\section{Avaliação de extratos preparados com vegetais secos sobre adultos de $C$. capitata}

Somente os extratos de fruto de cinamomo e gengibre tiveram efeito inseticida sobre adultos de C. capitata, diferindo-se do tratamento testemunha (Tabela 5).

Diferentemente do que foi observado para as fases de larva e pupa de C. capitata, em que o efeito inseticida do extrato de cinamomo ocorreu devido à interferência no processo de ecdise e metamorfose, para a fase adulta este extrato provavelmente causou deterrência, reduzindo o consumo alimentar e causando sua morte.

O principal efeito de extratos obtidos a partir das plantas de cinamomo sobre os insetos é a fagoinibiçáo ou deterrência, causada por substâncias tais como limonoides e triterpenoides (CARPinella et al., 2003). De acordo com Mordue; Nisbet (2000), a deterrência é

Tabela 5. Porcentagem de mortalidade média ( \pm EP) de adultos mortos e número médio de larvas desenvolvidas de Ceratitis capitata em frutos de ameixa vermelha após exposição a diferentes extratos preparados com vegetais secos.

\begin{tabular}{lrc} 
Tratamento & $\begin{array}{c}\% \text { mortalidade } \\
\text { de adulto }\end{array}$ & $\begin{array}{c}\text { Número de } \\
\text { larvas }^{1}\end{array}$ \\
\hline Testemunha & $0,00 \pm 0,00 \mathrm{c}$ & $5,43 \pm 0,30 \mathrm{a}$ \\
\hline Fruto de cinamomo & $25,71 \pm 3,69 \mathrm{a}$ & $4,57 \pm 0,53 \mathrm{a}$ \\
\hline Folha de cinamomo & $0,00 \pm 0,00 \mathrm{c}$ & $4,71 \pm 0,64 \mathrm{a}$ \\
\hline Ramo de cinamomo & $0,00 \pm 0,00 \mathrm{c}$ & $5,00 \pm 0,79 \mathrm{a}$ \\
\hline Gengibre & $5,71 \pm 3,69 \mathrm{~b}$ & $5,14 \pm 0,46 \mathrm{a}$ \\
\hline Alho & $0,00 \pm 0,00 \mathrm{c}$ & $6,43 \pm 0,30 \mathrm{a}$ \\
\hline Arruda & $0,00 \pm 0,00 \mathrm{c}$ & $5,43 \pm 0,61 \mathrm{a}$ \\
\hline CV (\%) & 99,53 & 27,46
\end{tabular}

'médias seguidas da mesma letra na mesma coluna não se diferem entre si pelo teste Scott-Knott ( $p \leq 0,05 \%)$;

${ }^{2}$ dados originais em porcentagem apresentados e transformados em $\operatorname{arcsen} \sqrt{\mathrm{x} / 100}$ para análise. um distúrbio que está associado aos mecanismos sensoriais do inseto e que causa a redução do consumo de alimento. Para tais autores, o comportamento alimentar dos insetos depende da integraçáo do sistema nervoso central com os quimiorreceptores localizados nos tarsos, nas peças bucais e na cavidade oral. Determinadas substâncias, tais como aquelas encontradas em plantas de cinamomo, podem atuar sobre os quimiorreceptores, estimulando as "células deterrentes específicas" ou bloqueando os fagoestimulantes, como as "células receptoras de açúcar", inibindo a alimentação. A reduçấo no consumo alimentar provoca deficiência nutricional, podendo causar redução na capacidade de movimentação, atraso no desenvolvimento, deformaçóes e morte do inseto (Costa et al., 2004).

Nas condições estudadas, os extratos não tiveram efeito sobre a oviposição de C. capitata (Tabela 5). SALLes; Rech (1999) avaliaram diferentes concentraçôes $(0,30,60,90,120$ e $150 \mathrm{~g} / \mathrm{L})$ do extrato do fruto de cinamomo sobre $A$. fraterculus e também verificaram que o mesmo não interferiu no número de ovos colocados por fêmeas, aumentando, no entanto, a quantidade de adultos deformados.

Zappata et al. (2006) verificaram que o extrato aquoso de Cestrum parqui (Solanaceae) (planta venenosa nativa da América do Sul) reduziu a oviposição de C. capitata em aproximadamente $85,0 \%$ em relação ao tratamento testemunha e causou mortalidade em torno de 70,0\% em adultos após cinco dias de exposição. Vale ressaltar que, no presente trabalho, os adultos de C. capitata ficaram expostos ao extrato vegetal por apenas dois dias, podendo ser este um período curto para afetar a fecundidade das fêmeas.

Os resultados do presente trabalho comprovam que os extratos de cinamomo, arruda, alho e gengibre possuem propriedades inseticidas e tiveram efeito sobre larvas e pupas de C. capitata, com destaque para o primeiro, o qual teve um resultado também sobre a fase adulta desse inseto. Nenhum dos extratos estudados interferiu na fecundidade das fêmeas de C. capitata. Extratos preparados com vegetais secos foram mais eficientes em relação àqueles com frescos, provavelmente por garantir a extraçáo de uma maior quantidade de substâncias bioativas.

No presente trabalho houve exposição máxima entre o inseto e o extrato vegetal. Portanto, são necessários novos estudos para avaliar o efeito de tais compostos em condições de cultivo protegido e campo e aquele dos extratos obtidos a partir dos diferentes métodos de extração e solventes, os quais são determinantes para garantir a extração das substâncias bioativas. Também são necessárias pesquisas para determinar os compostos bioativos presentes nestas plantas e o modo de ação sobre os insetos. 


\section{REFERÊNCIAS}

ALMEIDA, F.A.C.; GOLDFARB, A.C.; GOUVEIA, J.P.G. Avaliação de extratos vegetais e métodos de aplicação no controle de Sitophilus spp. Revista Brasileira de Produtos Agroindustriais, v.1, n.1, p.13-20, 1999.

ANDRADE-COELHO, S.N.A.; GOUVEIA, C.; SILVA, V.C.; GONZALEZ, M.S.; RANGEL, E.F. Effect of fruit and leaves of meliaceae plants (Azadirachta indica and Melia azedarach) on the development of Lutzomyia longipalpis larvae (Diptera: Psychodidae: Phlebotominae) under experimental conditions. Journal of Medical Entomology, v.46, n.5, p.1125-1 130, 2009.

BARBOSA, S.L.; LEITE, G.L.D.; MARTINS, E.R.; GUANABENS, R.E.M.; SILVA, F.W.S. Métodos de extração e concentrações no efeito inseticida de Ruta graveolens L., Artemisia verlotorum Lamotte e Petiveria alliacea L. a Diabrotica speciosa Germar. Revista Brasileira de Plantas Medicinais, v.1 1, n.3, p.221-229, 2009.

BARBOSA, F.S.; LEITE, G.L.D.; ALVES, S.M.; NASCIMENTO, A.F.; D'AVILA, V.A.; COSTA, C.A. Insecticide effects of Ruta graveolens, Copaifera langsdorffii and Chenopodium ambrosioides against pests and natural enemies in commercial tomato plantation. Acta Scientiarum Agronomy, v.33, n. 1, p.37-43, 2011.

BRUNHEROTTO, R.; VENDRAMIM, J.D. Bioatividade de extratos aquosos de Melia azedarach L. sobre o desenvolvimento de Tuta absoluta (Meyrick) (Lepidoptera: Gelechiidae) em tomateiro. Neotropical Entomology, v.30, p.455-459, 2000.

CABRAL, M.M.O.; ESTEBRAN, R.F.; MENDONÇA, P.M.; GOMES C.M.S.; OLIVEIRA, V.C.; KELECOM, A. Melia azedarach L. extracts and their activity on Musca domestica L. (Diptera: Muscidae). Revista Brasileira de Farmacognosia, v. 18, p.699-702, 2008.

CABRAL, M.M.O.; KELECOM, A.; GARCIA, E.S. Effects of the lignan, pinoresinol on the moulting cycle of the bloodsucking bug Rhodnius prolixus and of the milkweed Oncopeltus fasciatus. Fitoterapia, v. 70, p. 561-567, 1999.

CARPINELLA, M.C.; DEFAGO, M.A.; VALLADARES, G.; PALACIOS, S.M. Antifeedant and insecticide properties of a limonoid from Melia azedarach (Meliaceae) with potential use for pest management. Journal of Agricultural Food Chemistry, v. 51, p.369-374, 2003.

CHIFFELLE, I.G.; HUERTA, A.F.; LIZANA, D.R. Physical and chemical characterization of Lelia azedarach $\mathrm{L}$. fruit and leaf for use as botanical insecticide. Chilean Journal of Agricultural Research, v.69, n. 1, p.38-45, 2009.

COSTA, E.L.N.; SILVA, R.F.P.; FIUZA, L.M. Efeitos, aplicações e limitações de extratos de plantas inseticidas. Acta Biologica Leopoldensia, v.26, n.2, p.173-185, 2004.

DEQUECH, S.T.B.; SAUSEN, C.D.; LIMA, C.G.; EGEWARTH, R. Efeito de extratos de plantas com atividade inseticida no controle de Microtheca ochroloma Stal (Col.: Chrysomelidae), em laboratório. Biotemas, v.21, n. 1, p.41-46, 2008.
FERREIRA, D.F. Análise estatística por meio do SISVAR (Sistema para Análise de Variância) para Windows versão 4.0. In: REUNIÃO ANUAL DA REGIÃO BRASILEIRA DA SOCIEDADE INTERNACIONAL DE BIOMETRIA, 2000, São Carlos, Resumos, UFSCar, p.255-258, 2000.

HERNANDEZ, C.R.; VENDRAMIM, J.D. Uso de índices nutricionales para el efecto insectistatico de extratos de Meliáceas sobre Spodoptera frugiperda. Manejo integrado de plagas, v.48, p.79-88, 1998.

MARTINS, A.G.; ROSÁRIO, D.L.; BARROS, M.N.; JARDIM, M.A.G. Levantamento etnobotânico de plantas medicinais, alimentares e tóxicas da Ilha do Combu, Município de Belém, Estado do Pará, Brasil. Revista Brasileira de Farmácia, v.86, n. 1, p.21-30, 2005

MEDEIROS, A.R.M. Alelopatia: importância e suas aplicações. Hortisul, v.1, n.3, p.27-32, 1990.

MENEZES, E.L.A. Inseticidas botânicos: seus princípios ativos, modo de ação e uso agrícola. Embrapa Agrobiologia/ Documentos 205, 2005, 58p.

MORDUE, A.J.; NISBET, A.J. Azadirachtin from de neem tree Azadirachta indica: its actions against insects. Anais da Sociedade Entomológica Brasileira, v.29, p.615-632, 2000

NASCIMENTO, A.S.; CARVALHO, R.S. Manejo integrado de mosca-das-frutas. In: MALAVASI, A.; ZUCCHI, R.A. Moscas-dasfrutas de importância econômica no Brasil: conhecimento básico e aplicado. Ribeirão Preto: Holos, 2000. p.169-174.

SALLES, L.A.; RECH, N.L. Efeito de extratos de nim (Azadiractha indica) e cinamomo (Melia azedarach) sobre Anastrepha fraterculus (Wied.) (Diptera: Tephritidae). Revista Brasileira de Agrociência, v. 5, n. 3, p. 225-227, 1999.

SALVATORE, A.; BORKOSKY, S.; WILLINK, E.; BARDÓN, A. Toxic effects of lemon peel constituents on Ceratitis capitata. Journal of Chemical Ecology, v.30, n.2, 2004.

SANTIAGO, G.P.; PÁDUA, L.E.M.; SILVA, P.R.R.; CARVALHO, E.M.S.; MAIA, C.B. Efeitos de extratos de plantas na biologia de Spodoptera frugiperda (J. E. Smith, 1797) (Lepidoptera: Noctuidae) mantida em dieta artificial. Ciência e Agrotecnologia, v.32, n.3, p.792-796, 2008.

SANTOS, O.O.; MELO, E.A.S.F.; ROCHA, R.B.; OLIVEIRA, R.A.; BITTENCOURT, M.A. Atividade inseticida de produtos de origem vegetal sobre moscas-das-frutas (Diptera: Tephritidae) e broca-rajada (Coleoptera: Curculionidae). Magistra, v. 24, número especial, p.26-31, 2012.

SILVA, A.C. Efeito inseticida, deterrente e suppressor alimentar de alguns extratos vegetais sobre Ceratitis capitata (Wiedemann, 1824) (Diptera: Tephritidae) e Ascia monuste orseis (Latreille, 1819) (Lepidoptera: Pieridae) em laboratório. 1990. 129p. 
Tese (Doutorado em Entomologia) - Universidade Federal de Lavras, Lavras, Minas Gerais, 1990.

SILVA, M.P.L.; ALVES, L.S.; SILVA, R.; SILVA, F. Atividade inseticida de extrato aquoso de gengibre Zingiber officinale $L$. no controle do pulgão preto Toxoptera citricida (Kirkaldy) (Hemiptera: Aphididae) em citros. In: VI CONGRESSO BRASILEIRO DE AGROECOLOGIA E II CONGRESSO LATINO AMERICANO DE AGROECOLOGIA, 2009. Resumos. Curitiba: UFPR, p.654-658, 2009.

VASCONCELOS, G.J.N.; GODIN JUNIOR, M.G.C.; BARROS R. Extratos aquosos de Leucaena leucocephala e Sterculia foetida no controle de Bemisia tabaci biótipo B (Hemíptera: Aleyrodidae). Ciência Rural, v.36, n.5, p.1353-1359, 2006.
WHITE, I.A.; ELSON-HARRIS, M.M. Introduction. In: Fruit flies of economic significance: their identification and bionomics. Australia: CAB International, 1992, p.1-14.

ZAPPATA, N.; BUDIA, F.; VINUELA, E.; MEDINA, P. Insecticidal effects of various concentrations of selected extractions of Cestrum parqui on adult and immature Ceratitis capitata. Journal of Economic Entomology, v.99, n.2 p.359-365, 2006.

ZUCCHI, R.A. Mosca-do-mediterrâneo, Ceratitis capitata (Diptera: Tephritidae). In: VILELA, E.F.; ZUCCHI, R.A.; CANTOR, F. Histórico e impacto das pragas introduzidas no Brasil. Ribeirão Preto: Holos, 2001. p.15-22. 